\title{
Chapter 14 \\ Integrated Assessment for Identifying Climate Finance Needs for Loss and Damage: A Critical Review
}

\author{
Anil Markandya and Mikel González-Eguino
}

\begin{abstract}
This chapter looks at what we can learn about possible Loss and Damage (L\&D) and finance needed to address it using economic Integrated Assessment Models (IAMs), which calculate economically optimal responses to climate change mitigation and adaptation in terms of maximising welfare (GDP) a few decades into the future. Interpreting modelled residual damages as unavoided $L \& D$, a few results emerge from the analysis. First, residual damages turn out to be significant under a variety of IAMs, and for a range of climate scenarios. This means that if adaptation is undertaken optimally, there will remain a large amount of damages that are not eliminated. Second the ratio of adaptation to total damages varies by region, so residual damages also vary for that reason. Third, residual damages will depend on the climate scenario as well as the discount rate and the assumed parameters of the climate model (equilibrium climate sensitivity) as well as those of the socioeconomic model (damage functions). These uncertainties are very large and so will be any projections of residual damages in the medium to long term. The chapter raises other aspects that could influence estimates of L\&D. An important one is that, since actual adaptation is very unlikely to be optimal, the amount of Loss and Damage may be influenced by the sources from which adaptation and Loss and Damage programs are financed. The level and structure of current limited financial resources is likely to result in adaptation that is significantly below the optimal level and thus result in significant L\&D.
\end{abstract}

Keywords Integrated Assessment Models $\cdot$ Loss and Damage $\cdot$ Residual damage $\cdot$ Adaptation $\cdot$ Mitigation

A. Markandya $(\varangle) \cdot$ M. González-Eguino

Basque Centre for Climate Change (BC3), Leioa, Spain

e-mail: anil.markandya@bc3research.org

(C) The Author(s) 2019

R. Mechler et al. (eds.), Loss and Damage from Climate Change, Climate Risk

Management, Policy and Governance, https://doi.org/10.1007/978-3-319-72026-5_14 


\subsection{Introduction}

The bulk of the literature on finance for addressing climate change in developing countries relates to mitigation and adaptation measures. The UNEP Emissions Gap Report (2015) and the Adaptation Gap Report (2016) provide a synthesis of the current available finance from different sources for activities under these categories, as well as likely finance needs in the future. There is little documented data on the difference between the adaptation needs and the levels of estimated impacts of climate change. This difference is generally referred to in the economics of climate change literature as the residual damages (Chambwera et al. 2014), and also in some of the literature, as the 'unavoided losses and damages (L\&D) from climate change' (see introduction by Mechler et al. 2018). Few estimates of the residual damages using economic modelling exist and there has not been sufficient discussion of the methodological choices and robustness of these model estimates. This chapter presents the underlying analytics and reviews the estimates of total climate change damages as gauged in the economic Integrated Assessment Model (IAM) literature ${ }^{1}$ for different mitigation scenarios as a basis for calculating residual damages. It discusses the uncertainties surrounding these estimates and provides interval estimates by region and (where possible) by country for selected countries. Uncertainty, discount rates and other methodological choices play an important role. We discuss these but focus on two important ones: sources of uncertainty inherent to IAM-Equilibrium Climate Sensitivity and damage functions, and how these will increase uncertainty of the damages and residual damages.

It is important to state that, while the damages from climate change are estimated here using IAMs and top-down damage functions, there is a far-reaching debate as to the proper economic methods to use for assessing economic damages and the cost of adaptation. Other methods utilised in the economics of climate change impacts (see Burke et al. 2016) range from improvements in bottom-up estimation of damages (Carleton and Hsiang 2016) to expert elicitation approaches (Pindyck 2016). Particularly, more research is now devoted to represent "non-market" damages such as changes in human health and biodiversity that could be sizeable, but are largely omitted from current estimates (see also Chambwera et al. 2014). Combining the estimates of total damages with those for adaptation, based on the same set of models, the chapter derives a set of estimates of possible L\&D for selected dates and under different RCP scenarios. Several issues challenging the robustness of these estimates are discussed in the chapter, including: ex ante versus ex post losses and damages, non-monetary damages, irreversibility and the role of economic growth in the affected countries. The chapter concludes with a discussion on what the IAM estimates imply for climate finance in the short and medium term, given the mandates and programmes of the main financing institutions, such as the Green Climate Fund.

\footnotetext{
${ }^{1}$ The economic IAM literature is to be distinguished from a scenario-based IAM literature where models, rather than calculating optimal responses to warming building on economic rationality, project future warming building on key drivers of climate change, including demographic variables, economic output, lifestyle and technology (see e.g. Nakicenovic et al. 2000).
} 


\subsection{Estimation of Residual Damages in Economic Integrated Assessment Modelling}

\subsubsection{IAM-Methods and Models}

Economic IAMs are a widely used class of models that explore the economic consequences of different growth paths in the presence of climate change with the objective of maximising social welfare (measured by GDP) over a specific time horizon (Ortiz and Markandya 2009). Several IAMs have been used in this field, with differences that are in part a matter of subjectivity in the modelling design. ${ }^{2}$ The IAMs tend to be quite aggregated, with a single measure of output (GDP), which increases over time through capital investment, population growth and technical change. In the model set-up, GDP is reduced as a result of losses or damages caused by climate change. These damages are included through functions that link damages in monetary terms to climate variables such as temperature or precipitation (typically temperature is the variable most commonly used). These functions and monetary damage estimates then feed into the model set-up to calculate the impact of the damages on economic output and growth, globally and for given world regions. Overall, the IAMs select levels of the control variables so as to maximise the discounted present value of welfare (usually represented by GDP or an adjusted version of GDP) over the chosen time horizon (usually 2100 or beyond). The key control variable has been the level of mitigation, but more recently adaptation has been added (the level of adaptation expenditures, which reduce climate-related damages). Levels of the control variables are selected as part of a dynamic welfare maximising exercise (generally in 10 year time steps and often until the year 2100) based on a trade-off between the costs climate change imposes and the reduction it makes to climate-related damages: as long as adaptation costs are smaller than damages avoided, climate change damages are reduced. The damages remaining after the adaptation has taken place are referred to as residual damages.

\subsubsection{IAM Mechanics: Relation Between Adaptation Expenditures, Loss and Damage and Residual Costs}

Figure 14.1 is a guide to understanding the links between total climate damages, expenditures on adaptation and residual damages. The vertical axis represents the value of damages in monetary terms. They can be thought of as damages in a single period or the present value of damages over the planning horizon. In the latter case additional issues arise about interpretation, which we discuss later. OD is the value of these damages in the absence of any adaptation.

\footnotetext{
${ }^{2}$ Further see Ortiz and Markandya (2009) for a detailed literature review of previous versions of IAMs for climate change analysis with damage functions mentioned here.
} 


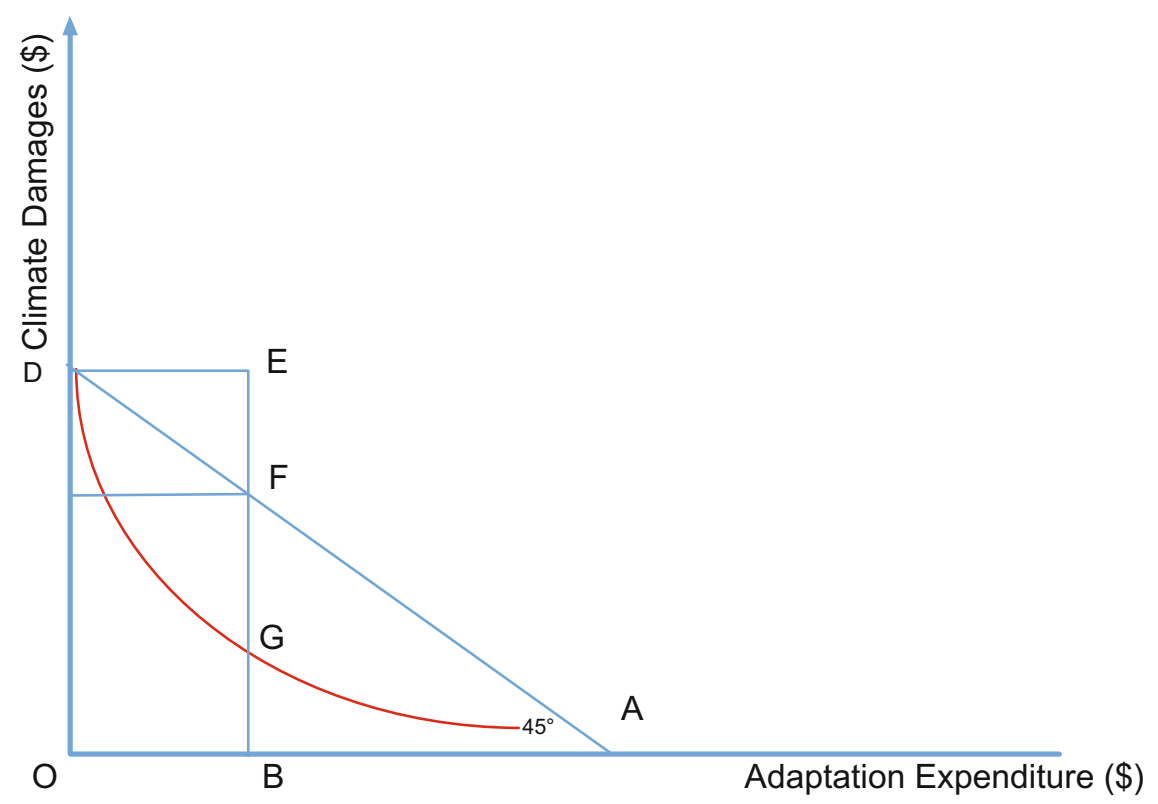

Fig. 14.1 Total damages, residual damages and adaptation expenditures

The horizontal axis measures total expenditure on adaptation, again either in a single period or as the present value over the planning horizon. The curve DA gives the damages corresponding to different levels of adaptation expenditure. It is convex to the origin because initial expenditures on adaptation yield greater reductions in damages than subsequent expenditures. As adaptation expenditure increases each unit generates less reduction than the unit before. It is also important to note that the curve starts with a slope of greater than one in absolute terms. This means that each million dollars spent on adaptation generates a reduction in damages for more than one million dollars. That is another way of saying that investment in adaptation, at least initially, has a cost that is less than the benefit.

The optimal level of adaptation expenditure is given by the distance OB, where the slope of the adaptation curve is equal to -1 . Further expenditure would have a cost greater than the reduction in damages, while less reduction on adaptation would not fully exploit the potential net benefits to be gained.

At this optimal level of adaptation expenditure damages fall by the amount EG, leaving a residual damage equal to GB. We can see the net benefits of adaptation as the difference between the reduction in damages (EG) and the cost $(\mathrm{OB}=\mathrm{EF}$, by construction). Hence FG is the net benefit from the adaptation. Of course, damages 'beyond adaptation' are still very important — and at the heart of the Loss and Damage debate. With optimal adaptation they are equal to GB, and this could be a very large amount, especially when adaptation is not optimal but even when it is. The above analysis is based on adaptation being undertaken in an optimal fashion. Note 
that it implies some residual damage and, furthermore, it implies a total cost of climate damage after adaptation that is less than it would be with no action, even after accounting for adaptation expenditures. When adaptation is less than optimal residual damages will be larger.

The above analysis also has a time dimension, which can be simplified by assuming that damages and adaptation expenditures are represented in present value terms. In doing so we abstract from the problem of when the adaptation expenditures are to be made and when the residual damages will occur. The dynamic solution to the adaptation programme is, as we see in the next section, partly a function of the discount rate. The higher the discount rate taken, the less mitigation is undertaken and the greater are total damages likely to be. This implies some more adaptation but the net effect on residual damages, while not totally clear, is likely to be higher than with the lower discount rate. Since there is no agreement on the choice of discount rate there will also not be one on desired adaptation in the future and on residual damages that form the basis of the case for Loss and Damage.

Finally, the choice of adaptation versus residual damages for a given country will be influenced by what is financed internally and what is financed externally. If adaptation is likely to be more fully covered from external funds than compensation for residual damages the incentives will be to go for a higher level than the optimal OB shown in Fig. 14.1. On the other hand, if residual damages are more fully compensated and adaptation has to be financed to a greater degree from internal sources, the incentive will be to aim for a lower level of adaptation than OB. All these factors will play a role in determining how much adaptation actually takes place and how much residual damage arises as a result of climate change.

\subsection{Estimating Residual Damages as a Measure of Loss and Damage}

\subsubsection{Model Set-Up}

In this section we provide estimates of residual damages from a range of IAMs, taking account of uncertainty in the damage functions. The basic model ensemble is that of Bosello et al. (2010), which gives perhaps the most detailed time profile for adaptation costs and residual damages from a range of IAMs. The steps involved in making the estimates are the following:

The Base Cases considered are ones in which the temperature increases by $2.5^{\circ} \mathrm{C}$ by the end of this century, which is consistent with concentrations stabilising at around $650 \mathrm{ppm}$ (IPCC 2014) and implies moderate success in limiting emissions to the 'low damage' scenario. We can also refer to this as the low emissions scenario. By contrast, in the high emissions/high damage scenario the equivalent temperature increase is around $3.4{ }^{\circ} \mathrm{C}$. In addition, the discount rate, which represents a societal preference for enjoying (consuming) any economic gains today rather than in a distant 


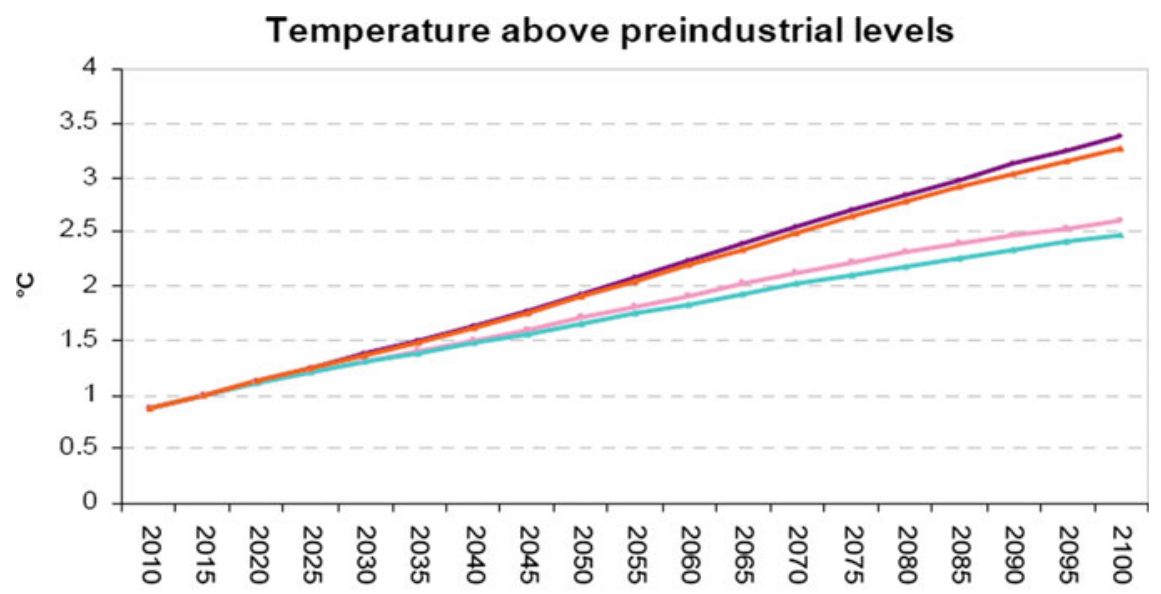

\section{LDAM_LDR —LDAM_HDR —HDAM_LDR —HDAM_HDR}

Fig. 14.2 Temperature pathways for low and high damage scenarios

future, specifies the level that future additions to welfare are reduced-a standard procedure in economics, however with heated debate as to the level of discounting (see further below).

Figure 14.2 shows the temperature pathways for four scenarios: (i) low damage/low emissions with a low discount rate (LDAM-LDR), (ii) low damage/low emissions with a high discount rate (LDAM-HDR), (iii) high damage/high emissions with a low discount rate (HDAM-LDR), and (iv) high damage/high emissions with a high discount rate (HDAM-HDR). The high discount rate case is the one where the rate is set initially at 3\% and then declines over time as in the IAMs WITCH, DICE and RICE (see Nordhaus and Boyer 2000). The low discount rate is case is the one where the rate is set as $0.1 \%$ and then declines as in Stern (2007). To keep the analysis simple we consider only versions (ii) and (iii) of their analysis and use them to calculate residual damages over time. This provides a broad range of estimates.

For these cases Bosello et al. (2010) developed a version of the WITCH model to predict total damages. The model developed by Bosello et al. has 12 world regions (see regions further below in Tables 14.1 and 14.2). The model is run to obtain time profiles to 2100 for total global damages and expenditures on adaptation. Residual damages are only given globally, and in the model the regional share is assumed to be proportional to the regional share of damages. In order to obtain residual damages by region we take figures of total damages by region, which are reported for three IAMs: Nordhaus and Boyer (2000), AD-WITCH and the Bosello et al. (2010) model for the entire period. The average share of these total damages by region is calculated and then applied to the total residual damages by time period as given in Bosello et al. to obtain residual damages by region and time period for each scenario (all 

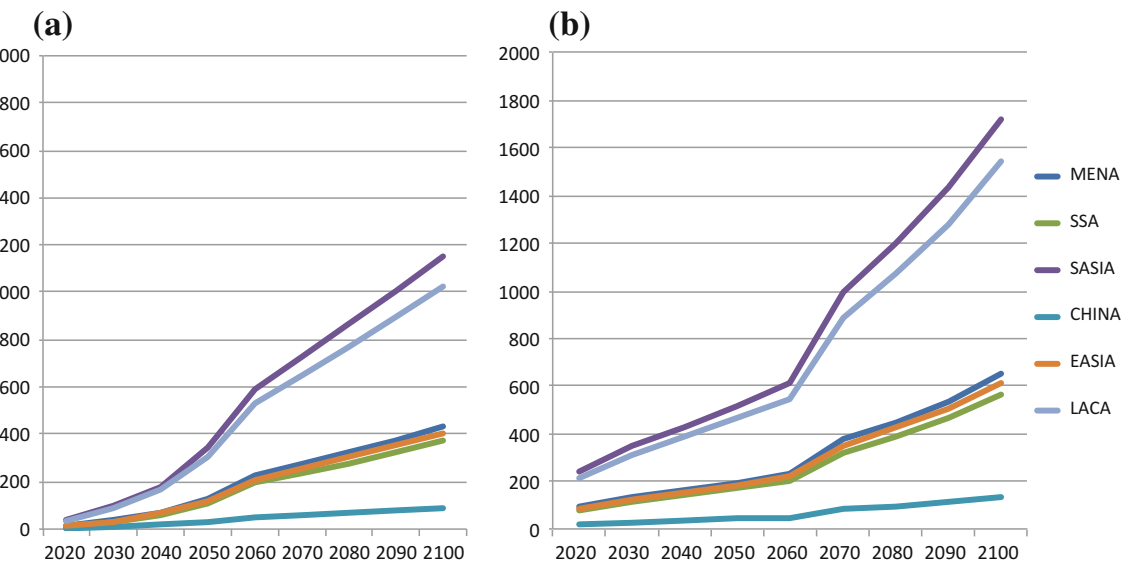

Fig. 14.3 Residual damages estimates for the case of a) low damages-high discount rate; b) high damages-low discount rate (in billion 2005 US)

estimates are given in billions of USD in 2005 prices). Damages are calculated for 12 regions and for every decade from 2020 to 2100.

\subsubsection{Results}

The estimates are shown in Tables 14.1 and 14.2. Table 14.1 gives residual damages in the high-damage/low discount rate case and Table 14.2 does the same for the low damage/high discount rate case. As stated, in each case the figures are for the averages of the three IAMs mentioned above. The last column in the two tables gives the range of damages across the three models, reporting the maximum as a percentage of the minimum. ${ }^{3}$ Finally the last row of Table 14.1 shows how much damages vary between the high and low damage cases by reporting the high damage as a percent of the low damage. The same information on regional damages is also shown in Fig. 14.3.

The figures show residual damages to vary significantly by region. Since we are interested in those damages that would need to be financed from a possible L\&D facility we can focus on the following regions, where the countries belong mainly to the non-Annex I group: MENA, SSA, SASIA, China, EASIA and LACA. Total residual damages for these regions range from $\$ 116-435$ billion in 2020 , rising to $\$ 290-580$ billion in 2030, $\$ 551-1,016$ billion in 2040 and $1,132-1,741$ billion in 2050. Thus, even in the low damages case the residual cost figures are substantial

\footnotetext{
${ }^{3}$ There are further variations in damages to consider for a given discount rate and a given temperature profile. These arise from the choice of key parameters of the IAMs and are discussed further in the next section.
} 


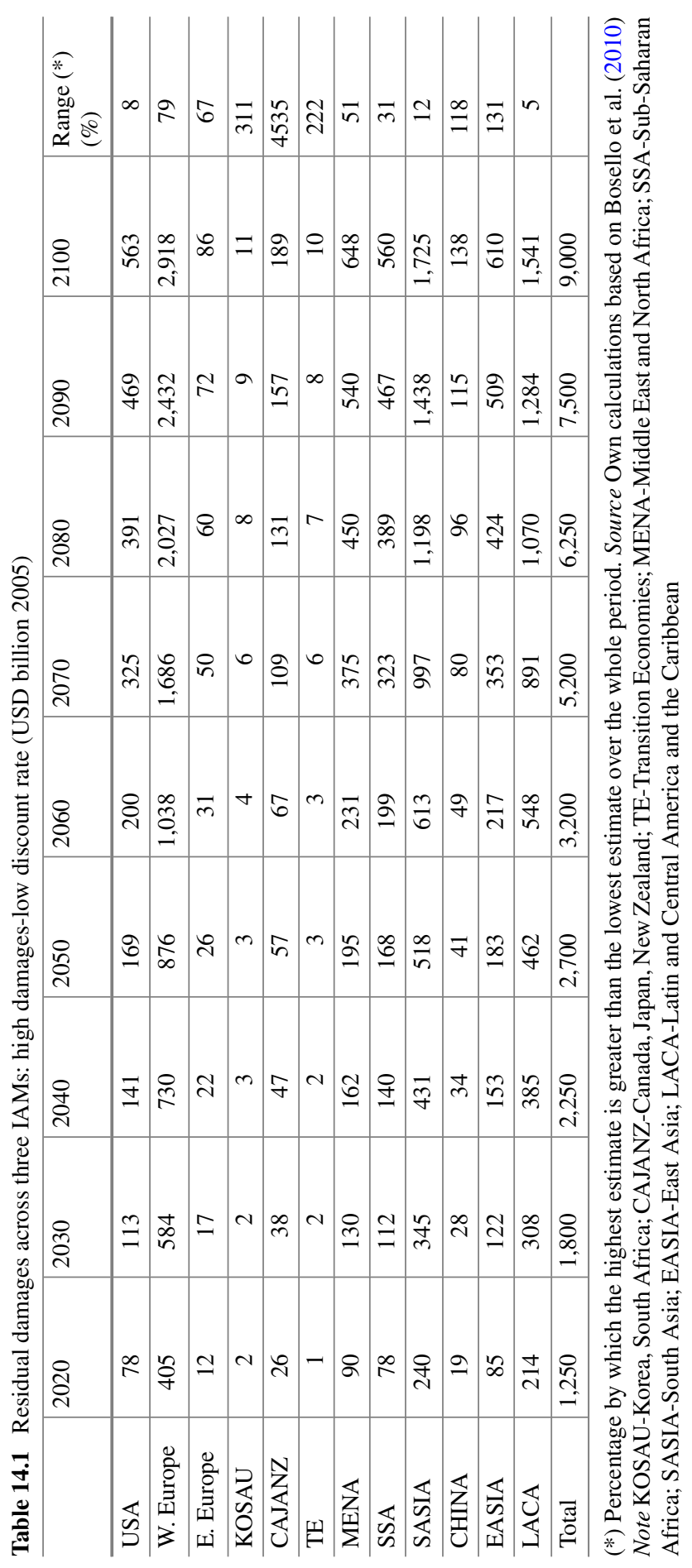


14 Integrated Assessment for Identifying Climate Finance Needs ...

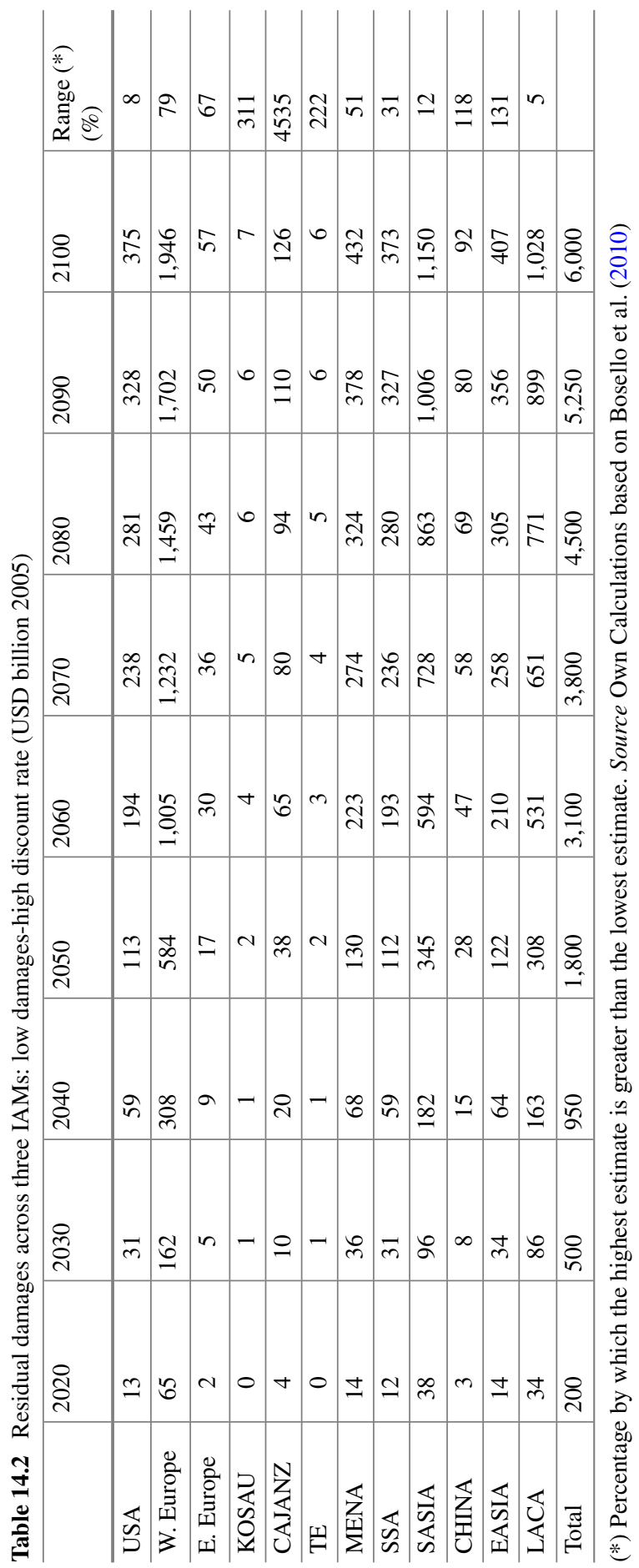


and in the high damage case they are more than double for the selected years to 2030. Over time the gap between the low damage and high damage estimates declines but by 2100 the high figure is still $150 \%$ of the low damage based residual cost.

The next point to note is the range of residual costs across IAMs. For the three models considered here, the highest estimates are 5-50\% greater than the lowest ones, with the exception of two regions: China and East Asia, where the range is much larger-around 100\%. This arises because the AD-WITCH model has much higher damage cost estimates for these two regions. Overall, the two sets of figures indicate two things: the fact that if $\mathrm{L} \& \mathrm{D}$ is to be based on residual costs the amounts involved will be significant, but the range of figures is still very wide.

\section{Loss and Damage-Residual Costs Versus Adaptation Costs}

It is also instructive to compare the residual costs with the adaptation cost estimates from the same modelling exercise. This will help put L\&D figures in context, given the focus on finance for adaptation. To keep the tabulations simple we limit the comparison to the Bosello et al. (2010) model. Tables 14.3 and 14.4 report both adaptation costs and residual costs as percent of adaptation costs. This is done only for the six regions/countries where $L \& D$ finance is likely to be an issue.

The tables and figures show that adaptation expenditures are relatively low compared to residual costs, which are 3-20 times higher to start with in 2020, but then decline, so that by 2100 they are $40-400 \%$ higher. There are also significant differences in the ratio of adaptation to residual costs across regions and scenarios. For China the difference is smallest, implying a larger share of costs are eliminated by adaptation, while in LACA, SASIA and SSA the ratios are very high, implying a relatively small contribution of adaptation to reducing climate damages. With the exception of estimates for 2020, the difference between residual costs and adaptation costs is greater with the low damage/high discount rate than with the high damage/low discount rate case; it appears that more adaptation is undertaken relative to total damage in the latter than in the former. The same information is also presented in Fig. 14.4.

\subsubsection{Implications of Higher Emissions and Greater Climate Impacts on Residual Damages}

The analysis presented has focussed on the case where equilibrium temperatures increase by $2.5-3.4^{\circ} \mathrm{C}$, implying some mitigation, but less than is required under the Paris accord. How much difference does it make if a lower reduction in temperature is attained? According to the IPCC AR5 report (Arent et al. 2014) estimates of global annual economic losses for additional temperature increases of $\sim 2{ }^{\circ} \mathrm{C}$ are incomplete, but lie in the range of between 0.2 and $2.0 \%$ of GDP ( \pm 1 standard deviation around the mean) (medium evidence, medium agreement). Losses are more likely than not to be greater, rather than smaller than this range (limited evidence, high agreement). Additionally, there are large differences between and within countries. 


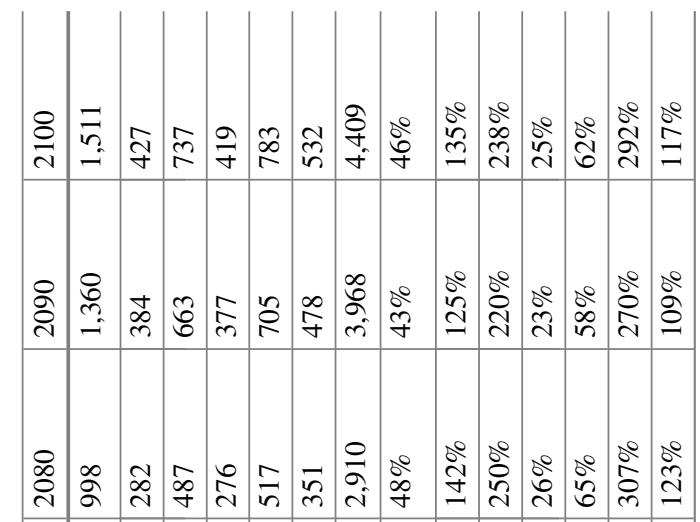

芒莒

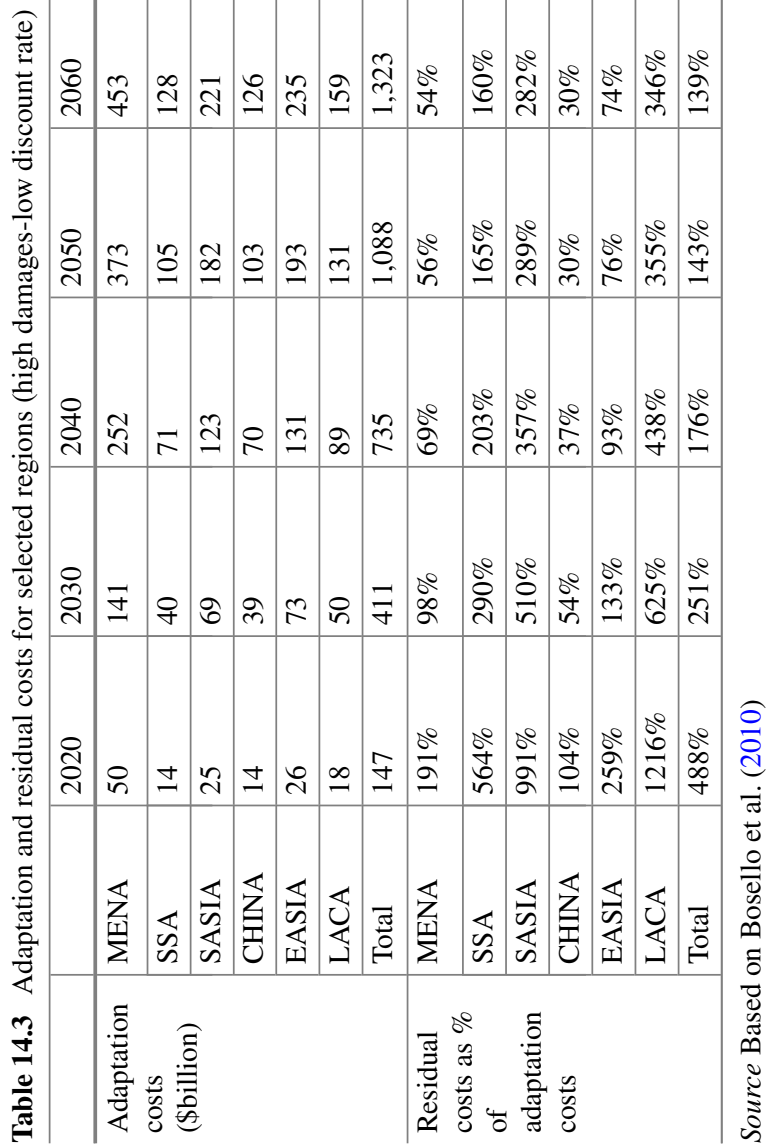







(a)

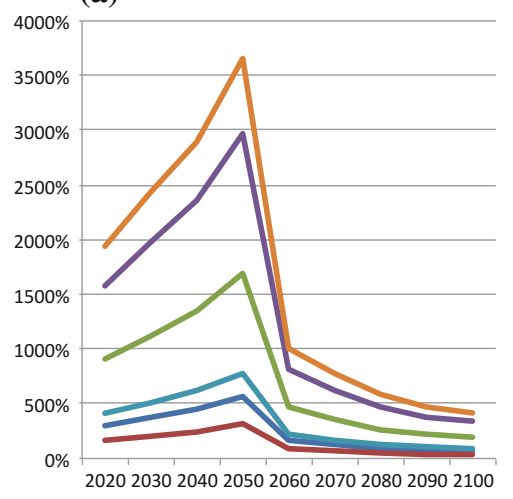

(b)

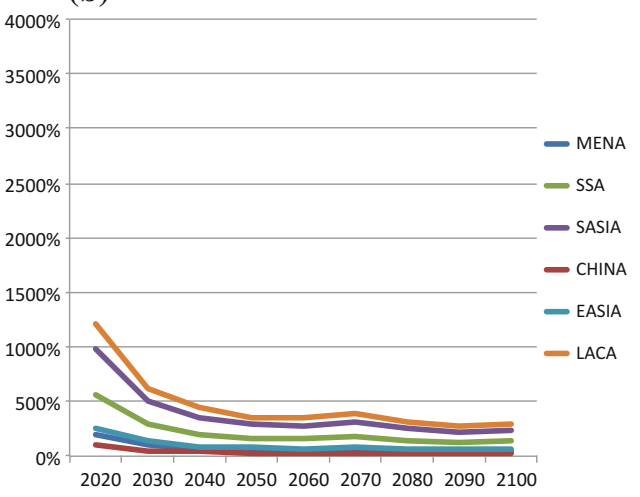

Fig. 14.4 Residual costs as percentage of adaptation costs for the case of a) low damages-high discount rate; b) high damages-low discount rate (in billion 2005 US)

Losses accelerate with greater warming (limited evidence, high agreement), but few quantitative estimates have been completed for additional warming around $3{ }^{\circ} \mathrm{C}$ or above.

At a regional level Bosello et al. (2010) find that the effects of increasing temperature are greatest for South Asia, followed by East Asia and Sub Saharan Africa and then by the Middle East (MDE). The sector most sensitive to temperature increases is agriculture, followed by tourism. Costs related to energy decline with temperature in this range (as reduced demand for heating dominates the increased demand for cooling). One can expect therefore a decrease in the temperature target to $2{ }^{\circ} \mathrm{C}$ or even $1.5{ }^{\circ} \mathrm{C}$ to result in residual costs that are correspondingly lower than the estimates given in Table 14.4.

We conclude this discussion by noting that these estimates are indicative of the results one gets from IAMs. Other models will generate different numbers, but we believe that the broad conclusions drawn from the review carried out here will remain valid. In the next section we focus on two relevant aspects of the IAM literature further to see why the results for climate damages and residual costs can vary so much.

\subsection{Discussion of Results}

The debate on the costs of climate change and finance generally, as well as specifically for L\&D is complex and has several dimensions, many of which are not well informed by the IAM analysis of residual damages. To put the discussion into context, estimates of damages, adaptation costs, L\&D and current available finance are worth noting.

The estimates of adaptation costs for developing countries have been estimated in a number of recent IAM studies, summarised in the UNEP Adaptation Gap Report 
(UNEP 2016). It states that the current internationally accepted best estimates for adaptation costs are in the US\$70 billion to US $\$ 100$ billion per year range for developing countries by 2050, according to a World Bank (2010) study. This compares with the range of US\$147-970 in the Tables 14.3 and 14.4. The UNEP report notes, however, that the World Bank (2010) study is outdated and more recent work based on two IAMs (AD-RICE and AD-WITCH) comes up with estimates of US\$200-450 billion (AD-WITCH) and US\$570-970 billion (AD-RICE). Thus, our range from the Bosello et al. analysis is similar to that of the UNEP (2016) report.

Other data on costs of adaptation and on L\&D damages worth noting are Bond (2016) and Richards and Schalatek (2017), who cite the following estimates:

- UNEP's Adaptation Gap Report (2014) estimates the indicative costs of adaptation and the residual damages (losses and damages) for LDCs at USD50 billion/year by $2025 / 2030$ and possibly double this value (USD100 billion/year) by 2050 at $2{ }^{\circ} \mathrm{C}$.

- Baarsch et al. (2015) suggest Loss and Damage costs (not needs) for developing countries of around $\$ 400$ bn in 2030, rising to \$1-2 trillion by 2050.

- DARA (2012) estimates these costs to be \$4 trillion in 2030.

- AMCEN/UNEP Africa's Adaptation Gap 2 Report (2015) with all cost effective adaptation in Africa losses and damages are estimated at $\sim$ USD100bn per year by 2050 for warming below $2{ }^{\circ} \mathrm{C}$, at least double that if warming goes above $4{ }^{\circ} \mathrm{C}$.

These estimates can be compared to the residual damages figures we have given in Sect. 14.2, which range from \$20-580 billion in 2030 to \$1.1-1.7 trillion in 2050. As Bond (2016) also notes, further work is required on the methodologies and processes for estimating L\&D and associated finance needs, as well as non-economic losses. It is in relation to these that the next section addresses some of the key outstanding issues. These include (i) issues relating to the time horizon under consideration and related uncertainty, and (ii) the relationship between adaptation expenditures and L\&D.

\subsection{Uncertainties in the Estimation of Future Damages from Climate Change in IAMs}

Recently, significant debate has emerged about the uncertainties (Pindyck 2013) associated with the quantification of the damages from climate change by IAMs. In the previous section, we provided a range for the residual damages under "standard" climatic conditions. In this section, we show these damages (and, therefore, the residual damages) would change significantly if "tipping points" are considered in the analysis (Lenton et al. 2008, 2012). There is much uncertainty related to these processes and, therefore, they have recently started to be captured in IAM literature in terms of implications for adaptation (Stern 2016) and mitigation (González-Eguino et al. 2016, 2017). We illustrate this through two key sources of uncertainty: the Equilibrium Climate Sensitivity (ECS) parameter and the damage function. 


\subsubsection{Climate Sensitivity and Damage Functions}

Equilibrium Climate Sensitivity (ECS) is one of the key parameters in climate science. ECS is defined as the equilibrium change in global temperature due to a doubling of atmospheric $\mathrm{CO}_{2}$ over its preindustrial value. This measure is typically characterised as a distribution due to underlying uncertainty in the behaviour of some aspects of the climate system. Studies based on observations, energy balance models, temperature reconstructions and global climate models (GCMs) have concluded that the probability density distribution of ECS peaks at around $3{ }^{\circ} \mathrm{C}$, with a long tail of small but finite probabilities of very large temperature increases. According to the IPCC's Fifth Assessment Report (IPCC 2013), estimates of the ECS indicate that it is likely to be in the range of $1.5-4.5^{\circ} \mathrm{C}$ (with high confidence) and very unlikely to be greater than $6{ }^{\circ} \mathrm{C}$ (medium confidence). The extreme temperature outcomes of the distribution function are sometimes referred to as "fat tails." Some authors (Weitzman 2009, 2012) have proposed that decisions on climate policy should actually be based on trying to avoid extreme outcomes of low probability. The uncertainty range of ECS has not been reduced substantially in the past three decades and it is not expected to be reduced in the near future (Roe and Baker 2007). Typically IAMs use the most likely value for ECS ( $3{ }^{\circ} \mathrm{C}$ as in Sect. 14.3.2), but it is important to perform a sensitivity analysis for different values for ECS.

The other major sources of uncertainty, in this case from climate change economics, is the way in which the damage function from global warming is represented (see Sect. 14.3.1). Damage functions are recognised as being one of the weakest links in the economics of climate change (Pindyck 2013), because it is very difficult to obtain empirical data and because results can be very sensitive to its functional form, particularly when high temperatures are considered. One of the most well-known damage functions is the one used by Nordhaus (DICE ${ }^{4}$ model, Nordhaus and Sztorc 2013), which has been recently adopted by the US Environmental Protection Agency (EPA 2010) to provide values for the social cost of carbon. However, in order to capture the possibility of "tipping points" and abrupt climate change, Weitzman (2012) has proposed a different damage function that captures large impacts beyond a $4-6{ }^{\circ} \mathrm{C}$ threshold based on an expert panel study involving 52 experts according to which at this temperature change three out of five important tipping points are expected to emerge (see Lenton et al. 2008). These authors mention different processes such as irreversible meltdown of the Greenland ice sheet, disintegration of the West Antarctic ice sheet, reorganisation of Atlantic thermohaline circulation, among others. Some of these processes may have a significant probability of occurring this century for climate conditions involving medium warming (between 2 and $4{ }^{\circ} \mathrm{C}$ ) and even low

\footnotetext{
${ }^{4}$ It is important to mention that DICE damage functions include the impacts after adaptation has occurred, so adaptation is already included. Some authors (see, for example, Bruin et al. 2009) have included the possibility of reducing damage through adaptation in IAMs so that they can therefore capture the trade-off between adaptation and mitigation.
} 

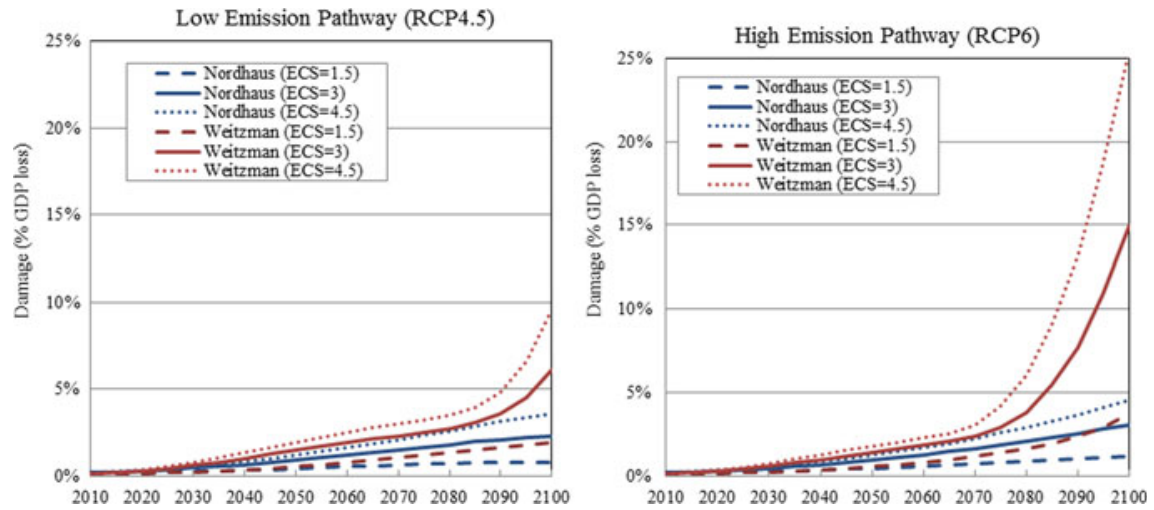

Fig. 14.5 Damage (\% GDP) for different damage functions and ECS parameters

warming $\left(<2{ }^{\circ} \mathrm{C}^{5}\right)$. Most modellers advise that at higher temperatures the damage functions go beyond their useful limits. Nordhaus, for example, suggests that we have insufficient evidence to extrapolate reliably beyond $3{ }^{\circ} \mathrm{C}$ (Nordhaus and Sztorc 2013). However, it is also true that there is a significant risk of temperatures rising above $3{ }^{\circ} \mathrm{C}$ in the course of this century.

Figure 14.5 shows the combined effect of the damage when the uncertainty in the ECS and in the damage function choice is considered. We show, using the DICE model, the damage (as \% of global GDP) for the Nordhaus and Weitzman damage functions and for three values for the ECS-1.5, 3 and 4.5. The damages are estimated for a low and high emission pathway scenario (RCP 4.5 and RCP 6), which are close to the ones reported in Sect. 14.3.2. We can see that the range of the damages is low before 2050 but then expands substantially at the end of this century. The damage per annum by 2100 in the low emission pathways could be $0.8 \%$ in the best case scenario (Nordhaus and ECS $=1.5$ ) and $9.5 \%$ in the worst (Weitzman and ECS = 4.5). Similarly, the damage in the high emission pathways could range between 1.2 and $25 \%$ in the more extreme situations.

Finally, and although IAMs have been helpful in illustrating the economic damage from climate change under different circumstances (Lenton and Ciscar 2012; Ackerman et al. 2010), these large uncertainties need to be recognised. Although the possibility of crossing a tipping point during this century is far from clear, it must be considered a possibility in any L\&D mechanism that could be designed. Similarly, any finance mechanisms implemented will need to be designed in the most flexible manner and considering this extreme situation so when new information is available it can be incorporated quickly as we will analyse in the following section.

\footnotetext{
${ }^{5}$ This is the case for example of the abrupt loss of Arctic summer sea ice or permafrost thawing (González-Eguino and Neumann 2016; Gonzalez-Eguino et al. 2017).
} 


\subsubsection{Time Horizon and L\&D Estimates}

With respect to the time horizon the following points are relevant: IAMs can help to provide an order of magnitude estimate for the resources that will be necessary to meet losses and damages estimates, but a bottom-up sector-by-sector analysis of existing and projected losses will be necessary. The challenge is to link the two approaches. At present we have the IAM analysis that draws on the bottom-up data in a rather crude way. The current bottom-up analysis for sectors such as agriculture, health etc. is more detailed but does not generally take account of the overall economic profile for the country or region. Uncertainty regarding future damages from climate change is very large in the long-term (2050-2100), especially if some tipping-points are crossed, but more moderate in the near (2020-2030) and medium-term (2030-2050). Thus, the longer the time horizon being considered the greater the uncertainty about the possible level of Loss and Damage. Some of these uncertainties are reduced significantly when mitigation is undertaken but also through adaptation. Previous sections show that low emission mitigation pathways can reduce future damages remarkably and their uncertainty range, and that adaptation measures can reduce residual damages.

In view of these facts one of the first objectives in the near term is for a L\&D finance mechanism to get established with the sufficient amount of monetary resources to cover the current existing losses directly attributed to climate change (not to natural variability). In the medium and the long term, it is important that the current design of financing mechanism is flexible enough in order to scale up the financing if and when necessary.

\subsection{Conclusions}

The aim of this chapter has been to see how much we can learn about possible losses and damages- and finance needed by employing economic IAMs, which are key analytical tools at the heart of economic analysis of the damages caused by climate change and of economically optimal responses to these damages. We interpret modelled residual damages as unavoided L\&D.

The current state of knowledge about damages has many gaps and we are not by any means at a stage where the results of these models can form the basis of financial packages of Loss and Damage. On the other hand, a few results stand out as relatively robust and credible, and provide a useful contribution to the Loss and Damage debate.

The first is that residual damages turn out to be significant under a variety of IAMs, and for a range of climate scenarios. This means that if adaptation is undertaken normally, there will remain a large amount of damage that is not eliminated. The figures for that damage vary by region and sector and provide a useful source of likely financial needs. Second the ratio of adaptation to total damages varies by region, so 
residual damages will also vary for that reason. Third, the residual damage figures will depend on the climate scenario, as well as the discount rate and the assumed parameters of the climate model (equilibrium climate sensitivity) as well as that of the socioeconomic model (damage functions). These uncertainties are very large and no one can make any meaningful projections of residual damages in the medium to long term.

The additional discussion in this chapter raises other aspects that could influence the levels of Loss and Damage. One is the fact that, since actual adaptation is very unlikely to be optimal, the amount of losses and damages may be influenced by the sources from which adaptation and L\&D programs are financed.

These findings may seem rather meagre in terms of informing the Loss and Damage debate, but we would contend that they still provide a useful guide to issues that need to be resolved. Certainly, there is scope for much more use of economic tools to understand economically efficient responses to future climate impacts. In the meantime, however, since financial commitments for L\&D are unlikely to be determined for more than 5 years ahead at any time, the models should focus on the potential Loss and Damage during that period, taking as given the adaptation programs that are relatively well determined for that period. As new information comes in, climate related damage estimation will improve as will the design of adaptation programs leading to improved use of these tools over time.

\section{References}

Ackerman F, Stanton E, Bueno R (2010) Fat tails, exponents, extreme uncertainty: simulating catastrophe in DICE. Ecol Econ 69(8):1657-1665. https://doi.org/10.1016/j.ecolecon.2010.03.0 13

Arent DJ, Tol RSJ, Faust E, Hella JP, Kumar S, Strzepek KM, Tóth F, Yan D (2014) Key economic sectors and services. In: Field CB, Barros VR, Dokken DJ, Mach KJ, Mastrandrea MD, Bilir TE, Chatterjee M, Ebi KL, Estrada YO, Genova RC, Girma B, Kissel ES, Levy AN, MacCracken S, Mastrandrea PR, White LL (eds) Climate change 2014: impacts, adaptation, and vulnerability. Part A: global and sectoral aspects. Contribution of working group II to the fifth assessment report of the intergovernmental panel on climate change. Cambridge University Press, Cambridge, United Kingdom and New York, NY, USA, pp 659-708

Baarsch F et al (2015) Impacts of low aggregate INDCs ambition: research commissioned by Oxfam. http://policy-practice.oxfam.org.uk/publications/impacts-of-low-aggregate-indcs-ambit ion-research-commissioned-by-oxfam-582427

BOND (2016) Finance for Loss and damage: marrakech and beyond. Development and Environment Group (DEG) Working Paper

Bosello F, Carraro C, De Cian E (2010) Market and policy driven adaptation. In: Lomborg B (ed) Smart solutions to climate change-comparing costs and benefits. Cambridge University Press, Cambridge, UK

Burke M, Craxton M, Kolstad CD, Onda C, Allcott H, Baker E, Barrage L et al (2016) Opportunities for advances in climate change economics. Science 352(6283):292-293. https://doi.org/10.112 6/science.aad9634

Carleton TA, Hsiang SM (2016) Social and economic impacts of climate. Science 353(6304):aad9837. https://doi.org/10.1126/science.aad9837 
Chambwera M, Heal G, Dubeux C, Hallegatte, S, Leclerc L, Markandya A, McCarl BA, Mechler R, Neumann JE (2014) Economics of adaptation. In: Climate change 2014: impacts, adaptation, and vulnerability. Part A: global and sectoral aspects. In: Field CB, Barros VR, Dokken DJ, Mach KJ, Mastrandrea MD, Bilir TE, Chatterjee M, Ebi KL, Estrada YO, Genova RC, Girma B, Kissel ES, Levy AN, MacCracken S, Mastrandrea PR, White LL (eds) Contribution of working group II to the fifth assessment report of the intergovernmental panel on climate change. Cambridge University Press, Cambridge, United Kingdom and New York, NY, USA, pp 945-977

DARA (2012) Climate vulnerability monitor (2nd Edition). A guide to the cold calculus of a hot planet. http://daraint.org/wp-content/uploads/2012/09/CVM2ndEd-FrontMatter.pdf

De Bruin KC, Dellink RB, Tol RSJ (2009) AD-DICE: an implementation of adaptation in the DICE model. Clim Change 95(1-2):63-81. https://doi.org/10.1007/s10584-008-9535-5

EPA (2010) social cost of carbon for regulatory impact analysis under executive order 12866 interagency, Working Group on Social Cost of Carbon, United States Government. http://onlinelibra ry.wiley.com/doi/10.1029/2011JD015804/epdf

González-Eguino M, Neumann M (2016) Significant implications of permafrost thawing for climate change control. Clim Change 136:381-388. https://doi.org/10.1007/s1058

González-Eguino M, Neumann MB, Arto I, Capellán-Perez I, Faria SH (2017) Mitigation implications of an ice-free summer in the Arctic Ocean. Earth's Future 5:59-66

IPCC (2013a) Climate change 2013: the physical science basis. In: Stocker TF, Qin D, Plattner G-K, Tignor M, Allen SK, Boschung J, Nauels A, Xia Y, Bex V and PM Midgley (eds) Contribution of working group I to the fifth assessment report of the intergovernmental panel on climate change. Cambridge University Press, Cambridge, United Kingdom and New York, NY, USA, 1535 pp

IPCC (2014) Climate change 2014. Synthesis report. Summary for policy makers. University Press, Cambridge, Cambridge

Lenton TM, Ciscar J-C (2012) Integrating tipping points into climate impact assessments. Clim Change 117(3):585-597. https://doi.org/10.1007/s10584-012-0572-8

Lenton TM, Held H, Kriegler E, Hall JW, Lucht W, Rahmstorf S, Schellnhuber HJ (2008) Tipping elements in the earth's climate system. Proc Natl Acad Sci 105(6):1786-1793. https://doi.org/1 0.1073/pnas.0705414105

Mechler R et al (2018) Science for loss and damage. Findings and propositions. In: Mechler R, Bouwer L, Schinko T, Surminski S, Linnerooth-Bayer J (eds) Loss and damage from climate change. Concepts, methods and policy options. Springer, Cham, pp 3-37

Nakicenovic N, Alcamo J, Davis G, de Vries B, Fenhann J, Gaffin S, Gregory K, Grübler A, Jung TY, Kram T, Emilio la Rovere E, Michaelis L, Mori S, Morita T, Pepper W, Pitcher H, Price L, Riahi K, Roehrl A, Rogner H, Sankovski A, Schlesinger M, Shukla P, Smith S, Swart R, van Rooyen S, Victor N, Dadi Z (2000) IPCC special reports: special report on emissions scenarios. Cambridge University Press, Cambridge, UK

Nordhaus WD and P Sztorc (2013) DICE 2013R: Introduction and User's Manual. http://www.ec on.yale.edu/ nordhaus/homepage/documents/DICE_Manual_103113r2.pdf

Nordhaus WD and JG Boyer (2000) Warming the world: the economics of the greenhouse effect. The MIT Press

Ortiz RA, Markandya A (2009) Integrated impact assessment models of climate change with an emphasis on damage functions: a literature review, BC3 Working Paper Series 2009-06 (October 2009)

Pindyck RS (2013) Climate change policy: what do the models tell us? J Econ Liter 51(3):860-872. https://doi.org/10.1257/jel.51.3.860

Pindyck RS (2016) The social cost of carbon revisited. w22807. National Bureau of Economic Research. http://www.nber.org/papers/w22807.pdf

Richards J-A, Schalatek L (2017) Financing loss and damage: a look at governance and implementation options. A discussion paper. Boell Foundation

Roe GH, Baker MB (2007) Why is climate sensitivity so unpredictable? Science 318(5850):629-632. https://doi.org/10.1126/science.1144735 
Stern N (2007) The economics of climate change. The stern review. Cambridge University Press, Cambridge, UK

Stern N (2016) Economics: current climate models are grossly misleading. Nature 530(7591):407. https://doi.org/10.1038/530407a

UNEP (2016) Adaptation gap report 2016. UNEP, Nairobi

Weitzman ML (2009) On modeling and interpreting the economics of catastrophic climate change. Rev Econ Statis 91(1):1-19. https://doi.org/10.1162/rest.91.1.1

Weitzman ML (2012) GHG targets as insurance against catastrophic climate damages. J Publ Econ Theor 14(2):221-244. https://doi.org/10.1111/j.1467-9779.2011.01539.x

World Bank (2010) Economics of adaptation to climate change: synthesis report. The World Bank Group, Washington, DC, USA, p 136

Open Access This chapter is licensed under the terms of the Creative Commons Attribution 4.0 International License (http://creativecommons.org/licenses/by/4.0/), which permits use, sharing, adaptation, distribution and reproduction in any medium or format, as long as you give appropriate credit to the original author(s) and the source, provide a link to the Creative Commons license and indicate if changes were made.

The images or other third party material in this chapter are included in the chapter's Creative Commons license, unless indicated otherwise in a credit line to the material. If material is not included in the chapter's Creative Commons license and your intended use is not permitted by statutory regulation or exceeds the permitted use, you will need to obtain permission directly from the copyright holder. 